\section{BMJ Open Respiratory Research}

\section{Rationale for azithromycin in COVID-19: an overview of existing evidence}

To cite: Gyselinck I, Janssens W, Verhamme P, et al. Rationale for azithromycin in COVID-19: an overview of existing evidence. BMJ Open Resp Res 2021;8:e000806. doi:10.1136/ bmjresp-2020-000806

- Additional material is published online only. To view please visit the journal online (http://dx.doi.org/10.1136/ bmjresp-2020-000806).

Received 20 October 2020 Revised 27 November 2020 Accepted 30 November 2020

\section{Check for updates}

(C) Author(s) (or their employer(s)) 2021. Re-use permitted under CC BY-NC. No commercial re-use. See rights and permissions. Published by BMJ.

${ }^{1}$ Respiratory Diseases, KU Leuven University Hospitals, Leuven, Flanders, Belgium ${ }^{2}$ Department CHROMETA Research group BREATHE, KU Leuven, Leuven, Flanders, Belgium

${ }^{3}$ Cardiovascular Diseases, $\mathrm{KU}$ Leuven University Hospitals, Leuven, Flanders, Belgium

${ }^{4}$ Centre for Molecular and Vascular Biology, KU Leuven, Leuven, Flanders, Belgium

Correspondence to Dr Iwein Gyselinck; iwein.gyselinck@kuleuven.be

\section{ABSTRACT}

Azithromycin has rapidly been adopted as a repurposed drug for the treatment of COVID-19, despite the lack of high-quality evidence. In this review, we critically appraise the current pharmacological, preclinical and clinical data of azithromycin for treating COVID-19. Interest in azithromycin has been fuelled by favourable treatment outcomes in other viral pneumonias, a documented antiviral effect on SARS-CoV-2 in vitro and uncontrolled case series early in the pandemic. Its antiviral effects presumably result from interfering with receptor mediated binding, viral lysosomal escape, intracellular cellsignalling pathways and enhancing type I and III interferon expression. Its immunomodulatory effects may mitigate excessive inflammation and benefit tissue repair. Currently, in vivo reports on azithromycin in COVID-19 are conflicting and do not endorse its widespread use outside of clinical trials. They are, however, mostly retrospective and therefore inherently biased. The effect size of azithromycin may depend on when it is started. Also, extended followup is needed to assess benefits in the recovery phase. Safety data warrant monitoring of drug-drug interactions and subsequent cardiac adverse events, especially with hydroxychloroquine. More prospective data of large randomised controlled studies are expected and muchneeded. Uniform reporting of results should be strongly encouraged to facilitate data pooling with the many ongoing initiatives.

\section{INTRODUCTION}

Since December 2019, the pandemic spread of the new virus SARS-CoV2 has affected over 50 million people. ${ }^{1}$ COVID-19-the disease caused by this virus-has killed over one million people in these past few months. Tremendous progress has already been made in the understanding of the disease. Still, only a few interventions have proven clinically beneficial and, besides thromboprophylaxis, these are mostly reserved for selected patients with an advanced disease stage. Their impact on the global disease burden, therefore, remains limited. ${ }^{2}$

A high initial viral load $^{3}$ and occurrence of a disproportional inflammatory response thereafter, the so-called cytokine storm, ${ }^{4}$ relate to adverse outcomes and are potentially modifiable. Hence, they are the target of most currently considered therapeutic strategies. Interference with the viral cycle is pursued through (1) inhibition of viral cell entry with TMPRRS2 inhibiting molecules such as camostat or aprotinin, (2) inhibition of viral lysosome escape with molecules as hydroxychloroquine, (3) antiretroviral drugs such as lopinavir/ritonavir that interfere with posttranslational processing through the main protease and (4) inhibition of viral RNAdependent RNA-polymerase with remdesivir or favipiravir. ${ }^{5}$ The excessive host's inflammatory response is mitigated by (1) broadspectrum molecules as dexamethasone ${ }^{6}$ or (2) targeted drugs as tocilizumab (antiinterleukin-6 (IL-6)), anakinra (anti-IL-1) or baricitinib (janus kinase inhibitor). Finally, anticoagulants are effectively used to counter the inflammation-induced hypercoagulative state. ${ }^{8}$ Overall, time pressure has sparked a special interest into the repurposing of marketed or late stage molecules for COVID-19, parallel to the development of new and more selective drugs. ${ }^{56}$

A repurposing drug candidate of special interest is azithromycin. Azithromycin is a macrolide antibiotic with a broad grampositive and gram-negative spectrum. Moreover, it has well-documented antiinflammatory and immunoregulatory effects, through modulation of both the innate and adaptive immune response. ${ }^{9}$ These are effective to treat chronic inflammatory disorders such as diffuse bronchiolitis, post-transplant bronchiolitis, non-eosinophilic asthma or rosacea. Azithromycin has also been associated with improved outcome in other viral pneumonias, such as influenza ${ }^{10}$ or rhinovirus, ${ }^{11}$ and in patients with acute lung injury admitted to the Intensive Care Unit (ICU).${ }^{12}$ This has in some centres led to the early adoption of azithromycin in routine COVID-19 care, 
further fuelled by reports of in vitro activity against SARS-CoV-2, and a suggested benefit in non-controlled case series early on in the SARS-CoV-2 pandemic. While more data of randomised controlled studies are eagerly awaited, we comprehensively review the rationale of its use against SARS-CoV-2, its window of opportunity and its possible limitations.

\section{PATHOPHYSIOLOGY OF COVID-19}

\section{Normal antiviral response}

SARS-CoV-2 is a positive-sense single stranded enveloped RNA $\beta$-coronavirus that spreads through aerosols, droplets, respiratory secretions and direct contact. ${ }^{13}$ One can distinguish different disease stages (figure 1). ${ }^{14}$ (A) After transmission, SARS-CoV-2 binds and enters respiratory epithelial cells through the ACE II (ACE2) receptor. ${ }^{15}$ The quick viral replication and high cytopathogenicity cause a strong release of danger signals, (B) Binding of these danger signals to specific pattern recognition receptors induces an innate antiviral immune response and clinical disease becomes apparent, $^{14}$ (C) In the following days an adaptive immune response is gradually mounted, comprising a T-helper-1 $\left(\mathrm{T}_{\mathrm{h}} 1\right)$ and often also a $\mathrm{T}_{\mathrm{h}} 2$ activation. ${ }^{16}$ In the latter case, anti-SARS-CoV-2 IIgM and IgG antibodies appear and their levels correlate with disease severity. ${ }^{17}$ Assuming the patient is able to overcome the infection, a convalescent phase commences and (D) Inflammatory markers decrease and, in most patients, pulmonary infiltrates slowly wane.

\section{Excessive inflammatory response: cytokine storm}

Severe COVID-19 is characterised by a disproportional inflammatory response. ${ }^{18}$ This has been attributed to multiple traits of SARS-CoV-2, some in analogy with
SARS-CoV and Middle East respiratory syndrome (MERS) (figure 2).

First, SARS-CoV-2 interferes with the innate antiviral immune response. Normally, two different antiviral pathways are activated. On the one hand, interferon (IFN) regulatory factors increase transcription of mainly type I and type III IFN, which stimulate natural killer cells and CD8 +cytotoxic T-lymphocytes. ${ }^{19}{ }^{20} \mathrm{On}$

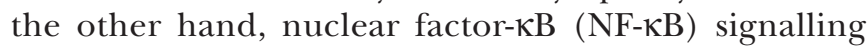
promotes monocyte activation and their differentiation into M1 macrophages. ${ }^{20}{ }^{21}$ These release proinflammatory cytokines and promote inflammatory T-cell $\left(\mathrm{T}_{\mathrm{h}} 1 /\right.$ $\mathrm{T}_{\mathrm{h}} 17$ ) activation. ${ }^{20-22}$ SARS-CoV-2 skews the innate response towards macrophage activation. It suppresses type I and III IFN-related gene transcription, thereby favouring NF- $\kappa \mathrm{B}$ activation. This impairs the recruitment of cytotoxic effector T-lymphocytes ${ }^{1623}$ and causes abundant cytokine release and inflammasome formation. $^{2024}$ In severely ill and ICU-admitted patients, macrophage-related cytokines IL-6, IL-10 and TNF $\alpha$ are indeed consistently elevated compared with milder cases. $^{1825}$

Second, excessive release of cytokines increases the expression of T-cell exhaustion markers, like programmed death 1 and $\mathrm{T}$ cell immunoglobulin and mucin domain-containing protein 3 (Tim-3) ${ }^{26}$ Together with IL-6 induced lymphocyte apoptosis and necrosis, ${ }^{22} 27$ T-cell exhaustion further dampens the cellular immune response. Lymphopenia is frequent and correlates with inflammation markers and disease severity. ${ }^{28}$

Third, binding of SARS-CoV-2 to ACE2 receptors, and their subsequent internalisation, reduces ACE2mediated angiotensin II breakdown. The increased angiotensin II levels enhance the inflammatory response, activate endothelial cells and locally increase
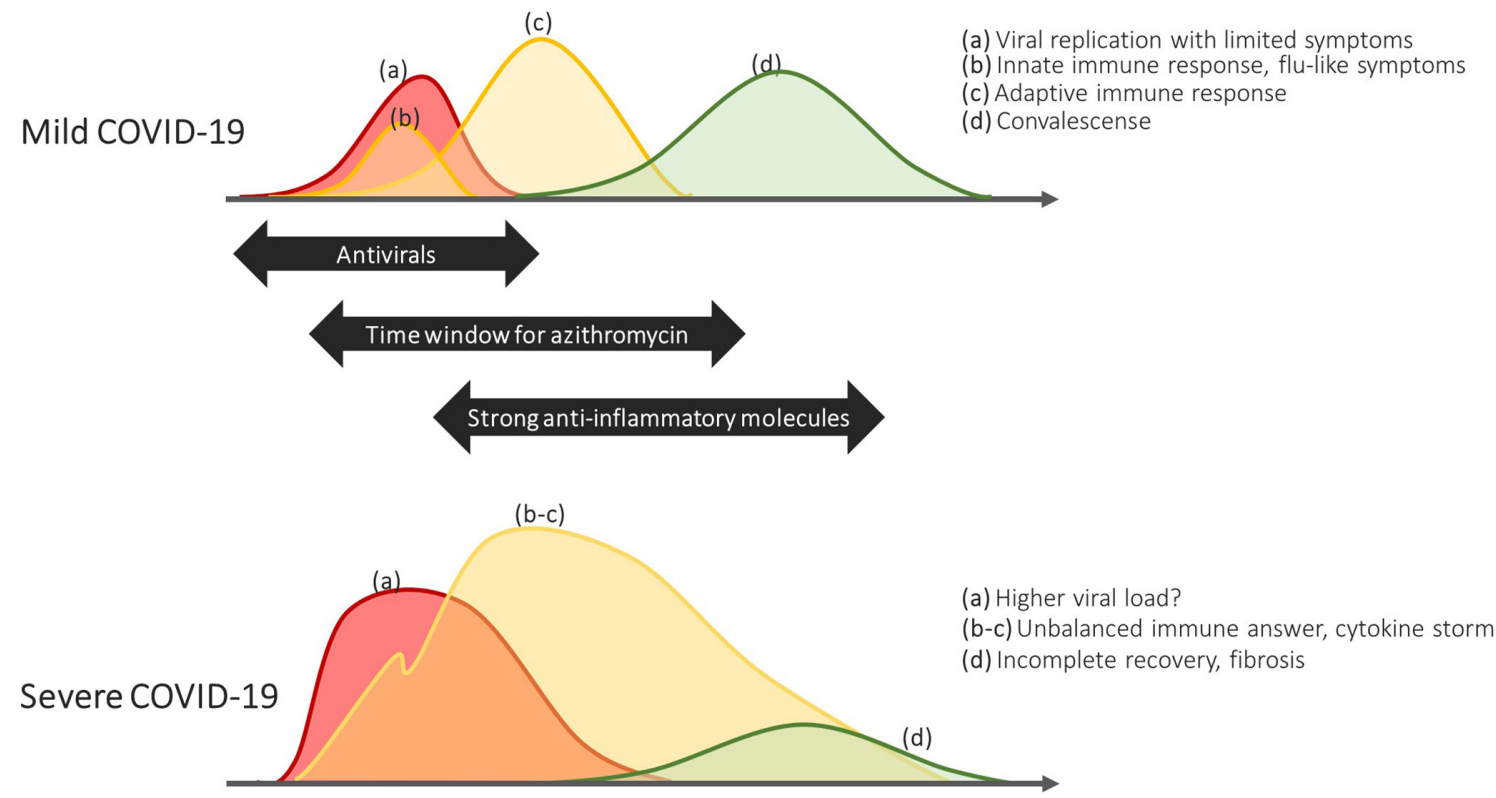

Figure 1 Chronology of the different disease-stages of COVID-19. 


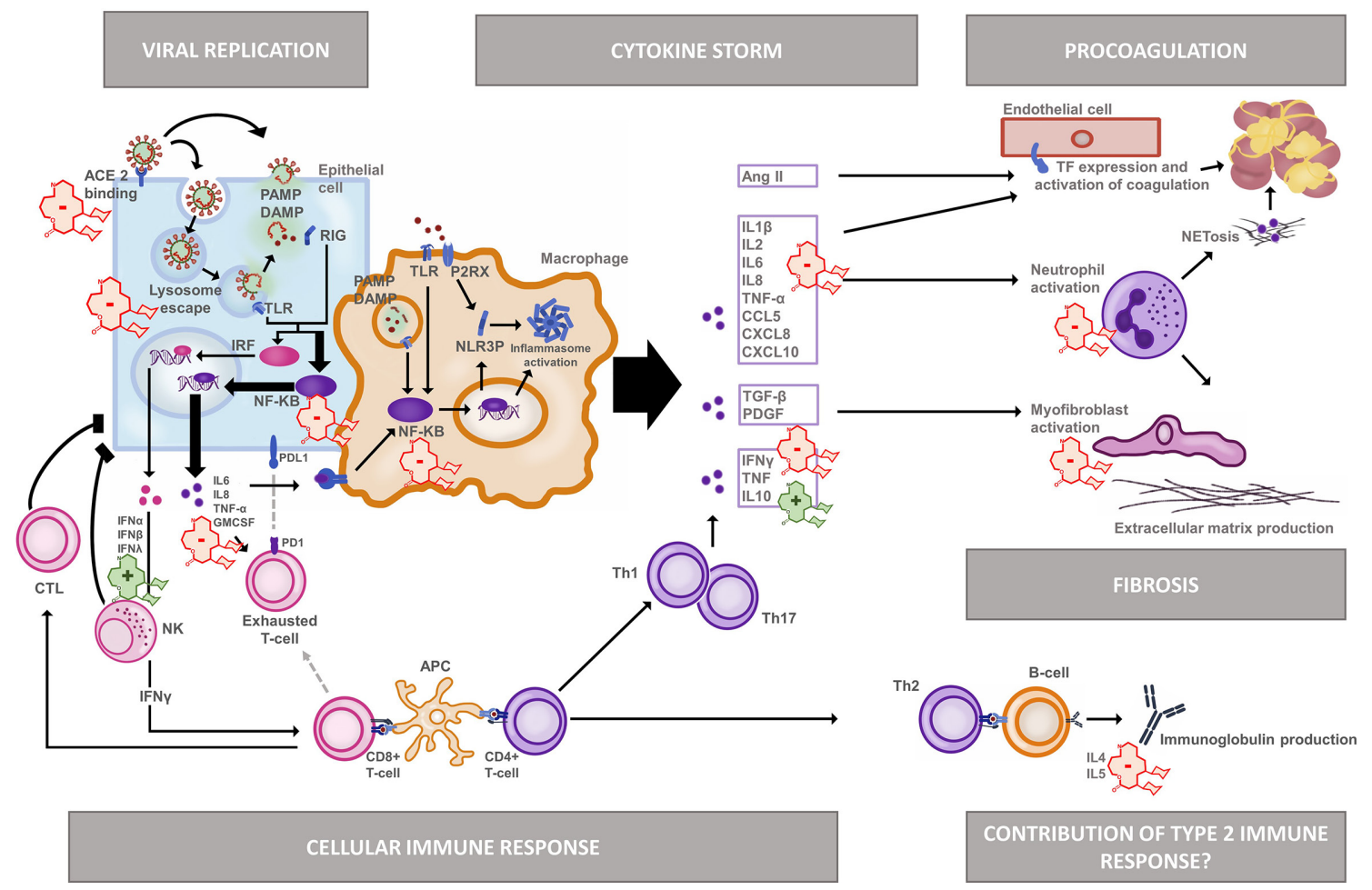

Figure 2 Azithromycin effects in the pathophysiology of COVID-19 after receptor-mediated endocytosis, both viral (PAMP) and host released (DAMP) molecules trigger antiviral pathways. SARS-CoV-2 induces a strong NF-KB pathway activation but supresses interferon-related gene transcription. This promotes macrophage activation and the release of pro-inflammatory cytokines and supresses an effective cellular immune answer. In severe COVID-19, this imbalanced immune answer causes a so called 'cytokine storm'. Neutrophils are drawn to the site of inflammation. Together with activated endothelial cells they contribute to hypercoagulation. They also contribute to a strong fibroblast activation, raising the concern for fibrotic complications in the long term. Current data shows that an effective Th2 response is more likely to occur in severe infection. It remains uncertain whether immunoglobulir s beneficial or rather enhances the acute inflammation by mechanisms such as antibody-dependent enhancement. 20 Azithromycin stimulatory and inhibitory immunomodulatory effects. Ang II, angiotensin I; CCL5, C-C motif chemokine ligand 5 (=RANTES); CTL, cytotoxic T-cell; CXCL, C-X-C motif chemokine ligand; DAMP, danger associated molecular pattern, GMCSF, granulocyte macrophage colony stimulating factor; IFN, interferon, IL, interleukin; IRF, interferon inducible factors; NET, neutrophil extracellular traps; NF-KB, nuclear factor kappa beta; NK, natural killer cell; NLRP3, nod-like receptor pyrin domain containing 3; P2RX, purinergic receptor P2X; PAMP, pathogen associated molecular pattern; PDGF, platelet-derived growth factor; RIG, retinoic acid inducible gene 1; Th, T helper cell; TLR, toll like receptor; TNF, tumour necrosis factor.

vascular permeability. ${ }^{29}$ This promotes coagulation by activation of the kallikrein-bradykinin system. A hypercoagulable state importantly contributes to COVID-19 morbidity and mortality. ${ }^{830}$

Finally, the excessive inflammation causes concern of pulmonary fibrosis as a possible late COVID-19 complication. ${ }^{31}$ In analogy with SARS and MERS, fibrotic changes have indeed been recognised in autopsy studies and may be associated with increased expression of tumour growth factor beta (TGF- $\beta$ ) and connective tissue growth factor. ${ }^{32}$ At this stage, it is still unclear who will recover, and who will proceed to uncontrolled cellular proliferation and persistent fibrotic remodelling.

\section{RATIONALE FOR AZITHROMYCIN USE IN COVID-19 Pharmacological profile}

Azithromycin is a 15-membered-ring macrolide of the azalide class. It is safe and, besides mild gastrointestinal side effects, usually well tolerated. ${ }^{33}$ QT-prolongation and cardiotoxicity are a concern, especially when combined with other QT-prolonging drugs. However, while clearly demonstrated for the 14-membered-ring macrolides such as erythromycin and clarithromycin, few reports relate azithromycin to cardiac adverse events. As opposed to 14-membered-ring molecules, azithromycin is not metabolised by cytochrome P450 (CYP450), which accounts for a more favourable drug-drug interaction profile. ${ }^{34}$

Azithromycin is rapidly absorbed after oral intake and has a long half-life. Its large volume of distribution is due to a high intracellular accumulation, with tissue concentrations up to a 100 -fold higher than in plasma. ${ }^{35}$ The uptake is particularly high in leukocytes, ${ }^{36}$ but also in epithelial cells and fibroblasts. Intracellularly, it 
has an affinity for acidic organelles such as lysosomes. Azithromycin also crosses the blood-brain barrier and concentrates in central nervous system tissue. ${ }^{37}$ This is noteworthy as there is increasing awareness of neurological complications of COVID-19, due to infiltration and activation of residing inflammatory cells and possibly direct viral neurotropism. ${ }^{38-40}$

In vitro data on the inhibitory concentrations of azithromycin on SARS-CoV-2 and other viruses have recently been summarised elsewhere. ${ }^{41}$ However, these data are scarcely replicated and far from an in vivo pharmacokinetic-pharmacodynamic target. On the other hand, azithromycin accumulation in leukocytes ensures effective delivery to sites of infection and inflammation. In vivo lung tissue homogenates reach concentrations well above the reported $90 \%$ effective concentration after 3 days of oral therapy with $500 \mathrm{mg}$ azithromycin. ${ }^{35}$ Similar regimens are approved and long used to treat bacterial gastroenteritis and respiratory tract infections. Slightly longer treatment durations of 5 up to 8 days were evaluated in cohorts studies assessing the effect of azithromycin in hospitalised patients with influenza ${ }^{10}$ or ICU patients with acute lung injury. ${ }^{12} 42$

\section{Antiviral effects}

Azithromycin has direct and indirect antiviral activity in bronchial epithelial cells ${ }^{43}$ and other host cells. In addition to SARS-CoV-2, this has also been shown for influenza, rhinovirus, dengue, ebolavirus, parainfluenza virus, zika virus and enterovirus. ${ }^{41} 44$

There are multiple mechanisms for azithromycin's antiviral effect. For host-cell entry, the prerequisite binding of the SARS-CoV-2 viral spike protein to ACE2 has been repeatedly described. Virtualised mechanical modelling techniques demonstrated that azithromycin may interfere due to its affinity with the binding interaction point of the spike protein and ACE2. ${ }^{45}$ Also, azithromycin may competitively inhibit a viral cofactor binding site due to its striking molecular similarity with GM1, a host-cell ganglioside that binds the ganglioside binding domain of the spike protein. ${ }^{46}$ Further experimental work is needed to confirm these possible modes of action. After receptor binding, the virus enters host cells either through membrane fusion, or through receptor mediated endocytosis. In the second route, endosome acidification facilitates viral escape and subsequent release of the nucleocapsid. Azithromycin interferes at this level, as it is a weak base that accumulates intracellularly and inside endosomes. ${ }^{41}$

During the remainder of the viral cycle, viruses are known to hijack intracellular antiapoptotic signalling pathways to promote their survival and replication. ${ }^{47}$ As an example, blocking the PI3K/AKT/mTOR-pathway decreases MERS-CoV replication in vitro. ${ }^{48}$ Rapamycin (sirolimus) is a known mammalian target of rapamycin (mTOR) -inhibiting macrolide, but azithromycin has also shown to interfere with mTOR-signalling, although to a lesser extent. ${ }^{48}{ }^{49}$ It remains unclear if and how this affects SARS-CoV-2 replication.

Furthermore, azithromycin also has indirect antiviral effects. It induces intracellular mRNA expression of antiviral genes, IFN-stimulated genes and IFN production in infected host cells. This may enhance the cellular antiviral response mediated by the IFN pathway and help to retain balance in the early innate immune response. ${ }^{435051}$

\section{Anti-inflammatory effect and modulation of macrophage action}

Azithromycin has well-documented immunomodulatory properties, that may affect the disease course of COVID19.

First, in in vitro models with respiratory epithelial cells azithromycin decreases mucus production and increases epithelial barrier thickness. ${ }^{52}$ It also reduces matrix metalloprotease (MMP) activity after challenge with bacterial lipopolysaccharides. This reduces inflammatory signalling, and helps to remain cell integrity and epithelial barrier function. ${ }^{52}$ These experiments have not been replicated with viral antigens. However, the related macrolide clarithromycin has shown to decrease lung and serum MMP-9 levels and vascular hyperpermeability due to influenza A infection in mouse models. ${ }^{53}$

Second, azithromycin is a potent modulator of monocyte and macrophage cytokine responses. It may balance the immune answer in COVID-19 by suppressing NF- $\mathrm{B}$ signalling ${ }^{54}$ and reducing release of classical M1 activated macrophage differentiation markers IL-8, IL-6, TNF $\alpha$ and granulocyte-macrophage colony-stimulating factor. ${ }^{34}$ Azithromycin promotes polarisation of macrophages from a M1 to an M2 phenotype, thereby augmenting their phagocytotic capacity. ${ }^{55}$

Third, azithromycin also modulates Th2-cell and B-cell responses. For example, it reduces the serum titre of specific IgG1-antibodies after vaccination with pneumococcal conjugate vaccine in mice. ${ }^{56}$ It is yet unclear how the antibody response contributes to the pathophysiology of COVID-19. Late neutralising antibodies seem to be protective. However, early IgG-response has been associated with more severe disease, possibly due to antibodydependent enhancement. ${ }^{57}$

Fourthly, azithromycin attenuates neutrophil function. It downregulates chemoattractants and adhesion molecules in activated vascular endothelial cells, reduces neutrophil activation and constrains the release of neutrophil extracellular traps (NET). ${ }^{34} 58$ Neutrophilia and NETosis contribute to hyperinflammation and hypercoagulability in severe COVID-19, ${ }^{59}$ but may be secondary to other processes like bacterial coinfection.

Finally, azithromycin attenuates TGF- $\beta$-induced myofibroblast differentiation, fibroblast collagen secretion and extracellular matrix remodelling. This occurs through a decrease of both MMP production ${ }^{60}$ and vascular endothelial growth factor release. ${ }^{61}$ Eventually, this limits the 
damaging effects of inflammation, fibrosis formation and vascular remodelling.

\section{Prophylaxis against bacterial superinfection}

The reported rate of antibiotic prescription in COVID-19 patients, especially in-hospital, is very high. ${ }^{62}$ Driving forces are the sometimes-difficult differential diagnosis with atypical pneumonias and fear of bacterial superinfection. Early bacterial coinfection has indeed been a wellknown source of morbidity and mortality in historic influenza pandemics. ${ }^{63}$ In COVID-19, however, pooled data suggest a much lower risk of bacterial co-infection, and do not support routine administration of antibiotics. ${ }^{64}$ Even though azithromycin may improve outcomes in the limited cases of superinfection, antibacterial prophylaxis is no grounded argument for its systematic use, and must be weighed against the risk of bacterial resistance.

\section{In vivo data}

Non-COVID-19

Azithromycin is an established treatment modality in several chronic inflammatory respiratory diseases. Different clinical trials have proven its efficacy in chronic obstructive pulmonary disease, bronchiectasis, asthma and lung transplantation. ${ }^{58}$ While undeniable proof of azithromycin's immunomodulatory potential, it is unsure if this can also be exploited in the acute setting.

Before COVID-19, the anti-inflammatory and antiviral effects of azithromycin have been clinically demonstrated in other viral pneumonias and in acute respiratory distress syndrome (ARDS). In a retrospective cohort evaluation of hospitalised patients with moderate or severe ARDS treated with azithromycin or not, azithromycin was associated with a significant improvement in 90-day survival rate and a shorter time to successful discontinuation of mechanical ventilation. ${ }^{42}$ Also, azithromycin-use was associated with decreased 60-day mortality and shorter time of ventilator dependency in patients with sepsis-associated ARDS. ${ }^{65}$ For the treatment of influenza, combination therapy of oseltamivir-azithromycin compared with oseltamivir alone showed improved clinical outcomes in a retrospective cohort ${ }^{10}$ and a faster decline of inflammatory parameters in a randomised controlled trial. ${ }^{66} \mathrm{On}$ the other hand, a tendency towards lower ICU mortality, lower 90-day mortality and shorter hospital stay did not achieve statistical significance in a cohort study on the use of macrolides (of which $71.3 \%$ was azithromycin) in critically ill patients with MERS. ${ }^{67}$ Possibly, the higher risk of coinfection in influenza, especially with influenza A, ${ }^{6364}$ may contribute to the larger effect size.

\section{COVID-19}

The positive reports on azithromycin in other respiratory viral diseases have prompted the rapid initiation of interventional trials to evaluate its efficacy in COVID-19. At the time of writing, 121 trials with azithromycin are listed in clinical trials.gov. At the start of the pandemic, however, following the example of early non-randomised series of a French group in Marseille, ${ }^{68} 69$ azithromycin has most often been prescribed as an adjuvant to hydroxychloroquine. The use of hydroxychloroquine is now largely abandoned and few published studies have assessed azithromycin alone. The reported effects of azithromycin are thus often derived from patients treated with hydroxychloroquine-azithromycin combination versus hydroxychloroquine alone. Table 1 gives an overview of currently published peer-reviewed studies in the MEDLINE database, in which the effect of azithromycin is assessed. Studies only comparing combination regimens versus standard of care were not considered (eg, hydroxychloroquine and azithromycin vs neither therapy), as no inference about the individual treatment effect of azithromycin could be deduced (see online supplemental material for detailed description of the individual studies and study selection).

Studies that assess azithromycin monotherapy versus standard of care in hospitalised patients report a wide effect range, from a decreased adjusted OR for mortality of 0.60 (95\% CI 0.42 to 0.85 ) in the retrospective cohort of Albani $e t a l^{70}$ to a non-significantly increased adjusted OR of 1.30 (95\% CI 0.65 to 2.64) in Kuderer et al. ${ }^{71}$ Even more heterogeneity is seen in studies that assess the addition of azithromycin to hydroxychloroquine, with a survival benefit (adjusted HR of 0.294; 95\% CI 0.218 to 0.396) seen by Arshad et al, ${ }^{72}$ opposed to a significantly increased 30-day mortality (adjusted OR 2.93; 95\% CI 1.79 to 4.79) reported again by Kuderer et al. ${ }^{71}$ In an outpatient setting, Guérin et $^{7 l^{33}}$ reported a significant reduction in the mean time to clinical recovery with azithromycin (12.9 days with azithromycin vs 25.8 days without; $\mathrm{p}<0.0001)$. A significant difference in hospitalisation risk was, however, not withheld by Szente $e t$ al. $^{74}$ (adjusted OR for azithromycincontaining vs no-azithromycin-containing regimens 0.93 ; $95 \%$ CI 0.72 to 1.90 ). The increased mortality reported for hydroxychloroquine-azithromycin combination by Kuderer $e t a l^{71}$ together with increased incidence of adverse events of this regimen in Rosenberg $e t a l^{75}$ and the randomised controlled trial of Cavalcanti et $a l^{76}$ strengthen the concerns about QT-prolonging drug-drug interactions. Importantly, no studies reported a significantly increased risk of adverse outcomes with azithromycin monotherapy. Cavalcanti et $a l^{76}$ did not assess efficacy of azithromycin monotherapy, but found no increased adverse events in this treatment group, whereas QTc prolongation and increased transaminases were seen in the hydroxychloroquine containing regimens. Similarly, Rosenberg $e t a l^{75}$ reported an increased incidence of cardiac arrest with hydroxychloroquine and azithromycin coadministration (adjusted OR, 2.13; 95\% CI 1.12 to 4.05) and when comparing hydroxychloroquine monotherapy with azithromycin monotherapy (adjusted OR, 2.97; 95\% CI 1.56 to 5.64) but not for azithromycin vs neither drug (adjusted OR, $0.64 ; 95 \%$ CI 0.27 to 1.56 ).

The interpretation of these heterogeneous results is troublesome in many ways. First, estimations of 


\begin{tabular}{|c|c|c|c|c|}
\hline & \multicolumn{2}{|l|}{ Inpatient } & \multicolumn{2}{|l|}{ Outpatient } \\
\hline & AZ alone & $A Z+H Q$ & AZ alone & $A Z+H Q$ \\
\hline $\begin{array}{l}\text { Studies favouring } \\
\text { AZ }\end{array}$ & $\begin{array}{l}\text { one retrospective study: } \\
\text { Albani et } \text { al }^{70}\end{array}$ & $\begin{array}{l}\text { Five retrospective } \\
\text { studies: } \\
\text { Arshad et } \text { al }^{72} \\
\text { Tanriverdi et } a l^{88} \\
\text { d'Arminio et } a l^{89} \\
\text { Sekhavati et } a l^{90} \\
\text { Lauriola et } a l^{91}\end{array}$ & $\begin{array}{l}\text { one retrospective } \\
\text { study: } \\
\text { Guérin et } \mathbf{a l}^{73}\end{array}$ & $\begin{array}{l}\text { one retrospective } \\
\text { study: } \\
\text { Guérin et } \text { al }^{73}\end{array}$ \\
\hline \multirow[t]{2}{*}{$\begin{array}{l}\text { Studies neutral to } \\
\text { AZ }\end{array}$} & 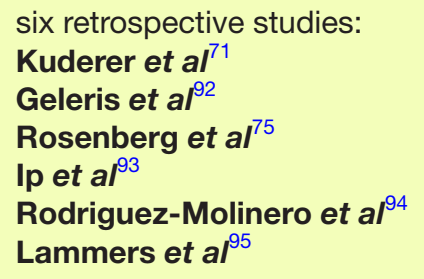 & $\begin{array}{l}\text { five retrospective } \\
\text { studies: } \\
\text { Satlin et } a^{96} \\
\text { Ip et } \mathbf{a l}^{93} \\
\text { Magagnoli et } \boldsymbol{a l}^{97} \\
\text { Ayerbe et } \mathbf{a l}^{98} \\
\text { Young et } a l^{99}\end{array}$ & $\begin{array}{l}\text { two retrospective } \\
\text { studies: } \\
\text { Kuderer et } \text { al }^{71} \\
\text { Szente } \text { et } \mathbf{a l}^{74}\end{array}$ & \\
\hline & $\begin{array}{l}1 \mathrm{RCT}: \\
\text { Cavalcanti et } \text { al }^{76}\end{array}$ & $\begin{array}{l}1 \mathrm{RCT}: \\
\text { Furtado et al }\end{array}$ & & \\
\hline \multirow[t]{2}{*}{$\begin{array}{l}\text { Studies not } \\
\text { favouring } A Z\end{array}$} & & $\begin{array}{l}2 \text { Retrospective studies: } \\
\text { Kuderer et } \text { al }^{71} \\
\text { Rosenberg et } \text { al }^{75}\end{array}$ & & $\begin{array}{l}\text { one retrospective } \\
\text { study: } \\
\text { Kuderer et } \text { al }^{71}\end{array}$ \\
\hline & & $\begin{array}{l}1 \mathrm{RCT}: \\
\text { Cavalcanti et } \text { al }^{76}\end{array}$ & & \\
\hline
\end{tabular}

PubMed was searched with the search term ('COVID-19' or 'SARS-CoV-2') and 'azithromycin'. A total of 537 titles and/or abstracts were screened. Studies that compared combination regimens and from which no individual treatment effect of azithromycin could be deduced were excluded.

$A Z$, azithromycin; $H Q$, hydroxychloroquine; $R C T$, randomised controlled trial.

azithromycin's individual treatment effect from combination regimens with hydroxychloroquine may be unsound. Drug-drug interactions may increase shortterm mortality and follow-up is often short to assess any long-term azithromycin benefits (eg, progression to fibrosis). Second, most of the studies are retrospective. State-of-the art statistical corrections like propensity score weighting are used in nearly half of the retrospective studies, but the propensities are often calculated on baseline patient characteristics like age, sex, comorbidities, obesity, while factors that have now been clearly associated with disease severity (eg, lymphopenia, D-dimers) are often not considered. This still allows significant indication bias in both directions, meaning more patients with milder disease are treated with azithromycin alone or neither drug and more severely ill patients are treated with combination treatment vs neither drug. Moreover, initiation of any form of treatment has been influenced by various factors other than baseline characteristics and disease severity, such as drug availability, do-notresuscitate orders and changing local policies. Third, the difference in techniques to adjust for confounders, but also the difference in primary outcomes (clinical improvement, mortality, hypoxia, hospitalisation risk), outcome measures (comparing odds vs time-to-event and survival analyses), target populations (mild vs severe, outpatients vs hospitalised patients) and follow-up times (in hospital mortality, 30-day mortality) all contribute to the heterogeneity and hinder data pooling for meta-analyses. We summarised the published metaanalyses that pooled azithromycin containing regimens (see online supplemental table A). They confirm the increased mortality risk in hydroxychloroquine-azithromycin cotreated patients. However, as they are largely based on the sometimes heavily biased data of the studies discussed above, one might still doubt a causal inference. The data of azithromycin monotherapy have not been pooled, and of the three meta-analyses that directly compared hydroxychloroquine with azithromycin versus hydroxychloroquine alone, only Das $e t a l^{77}$ found a significantly increased mortality with the addition of azithromycin. Interestingly, not cardiac adverse events but rather the development of severe disease was an outcome associated with the addition of azithromycin to hydroxychloroquine. As there is no mechanistic rationale to expect disease worsening with azithromycin, this may as well signal residual indication bias.

Overall, the limited and low-quality evidence does not endorse azithromycin's widespread use in the treatment of COVID-19. On the other hand, monotherapy is safe and therefore justifiable in a clinical trial setting. The data at least urges close monitoring when combined with other QT-prolonging drugs like hydroxychloroquine, or when other risk factors for long QT exist. A risk mitigation strategy such as applying strict ECG criteria to initiate (eg, only if QTc $<450)$ and halt (eg, if QTc exceeds $500 \mathrm{~ms}$ 
or increases $>60 \mathrm{~ms}$ since start of treatment) azithromycin may be warranted. ${ }^{78-80}$

\section{DISCUSSION}

The use of azithromycin in COVID-19 is mechanistically well grounded and indirectly supported by prior experiences with other viral pneumonias, chronic pulmonary diseases and inflammatory disorders. Yet, the empirical practice of azithromycin treatment for COVID-19 has not been substantiated by good quality clinical data. Despite-maybe even because of - the limitations, a critical appraisal of the currently available evidence is valuable. It should contextualise the results of ongoing trials and could improve the set-up of future trials.

First, most interventions have an optimal time window. From a mechanistic point of view, initiation of azithromycin before or during the early inflammatory phase is more sensible. At that early stage, an antiviral effect could still be relevant. It remains unclear, however, if azithromycin significantly inhibits viral replication in vivo. Better supported by the data in this review are the immunomodulatory effects of azithromycin on early inflammatory pathways that are key in the progression to severe COVID-19. They are supposed to balance the adaptive immune response, stimulate cellular immunity and avoid a subsequent cytokine storm. Results of large randomised controlled trials for hospitalised patients (eg, RECOVERY) ${ }^{81}$ are soon expected. However, a significant share of hospitalised patients may already be beyond this window. The primary care setting may be more suited to evaluate early interventions. Compared with the hospital though, this is a much less controlled environment, which makes retrospective data collection very challenging. A few studies are published, and the positive signals of Guérin $e t a l^{73}$ and Esper et $a l^{82}$ (preprint article, not included in table 1) are contradicted by Szente Fonseca et $a l^{74}$ At least, with only a short follow-up time needed to assess the risk of hospital admission, prospective data In this context (eg, ATOMIC2, ACTION) ${ }^{83} 84$ should soon be able to provide more clarity.

Second, despite the pleiotropic effects of azithromycin, it is certainly not the most potent molecule. Targeted antiviral drugs will likely have a more robust effect on the viral load. However, experience with influenza has taught us to start antivirals as soon as possible after host infection. ${ }^{85}$ Likewise, the anti-inflammatory effects of targeted anti-IL1, anti-IL6 or steroids are stronger, though probably only warranted when clear signs of hyperinflammation are present. ${ }^{86}$ If anything, one should not expect azithromycin to be put forward as 'the standard treatment', but rather as a part of a multimodal approach of antiviral, antithrombotic, anti-inflammatory andin selected cases-antibiotic drugs, depending on the patient's presentation, immune status and disease stage.

Lastly, it is important to consider treatment effects that surpass acute pulmonary inflammation. Azithromycin has antifibrotic properties and crosses the blood-brain barrier. Possible morbidity of sequellar fibrotic lung disease and of prolonged neurological complaints extends well beyond the acute phase, and attenuating this later phase will significantly impact quality adjusted life years of COVID-19 patients. A comprehensive clinical trial assessment with extended follow-up is, therefore, crucial to confirm or exclude the hypothetical benefits of azithromycin in COVID-19.

In conclusion, its favourable safety profile, affordability and pleiotropic mechanisms have raised a large interest in azithromycin to treat COVID-19. Its effect on the early inflammatory phase is best supported by the current evidence, which is typically when the first symptoms arise and a patient contacts his caretaker. Before starting azithromycin, a comprehensive assessment for drug-drug interactions and cardiovascular risk factors is prerequisite, especially when use in the first line is advocated. Beyond that, the current data remain equivocal. Due to the scale of the current pandemic, however, even a small treatment effect could mean a significant absolute reduction in COVID-19-related morbidity and mortality. Moreover, we have currently no idea on how a second primary infection will be eradicated by the hosts' primed immune system. Beneficial modes of action should not be discarded based on short-term results obtained during the first wave of hospital admissions. In the next months, results of adequately performed randomised trials will provide better insight into the true role of azithromycin and other repurposed drugs in this historic pandemic. Still, as the field of intervention studies in COVID-19 is currently highly scattered, large coordinated international initiatives will be needed to pool aggregated and individual patient data to come to optimal conclusions. ${ }^{87}$

Acknowledgements We would like to thank Dr Stijn Verleden (KU-Leuven) and Peter Brouw for their comments on the manuscript. We would like to thank the members of the DAWN-AZITHRO consortium for their support: Name Affiliation Kurt Vandeurzen, MD Mariaziekenhuis Noord Limburg, Pelt Lynn Decoster, MD AZ Turnhout, Turnhout Jean-Benoît Martinot, MD CHU-UCL Namur, Namur Pieter Goeminne, MD, PhD AZ Nikolaas, Sint Niklaas Hong Nguyen, MD Onze Lieve Vrouwziekenhuis, Aalst Eef Vanderhelst, MD, PhD UZ Brussel, Brussel Charles Pilette, MD, PhD Cliniques Universitaires Saint-Luc, Ottignies-Louvain-La-Neuve Ann-Catherine Soenen, MD Jan Yperman Ziekenhuis, leper Nikolaas De Maeyer, MD Jan Yperman Ziekenhuis, leper Nikolaas De Maeyer, MD Jan Yperman Ziekenhuis, leper Nikolaas De Maeyer, MD Heilig Hart Ziekenhuis, Leuven Aurelie Derweduwen, MD AZ Klina, Brasschaat Bernard Bouckaert, MD AZ Delta, Roeselare Patrick Alexander, MD AZ Glorieux, Ronse Emmanuelle Papleux, MD Hospitaux Iris Sud, Bruxelles Rob Schildermans, MD AZ St-Lucas, Brugge.

Collaborators Kurt Vandeurzen, MD; Lynn Decoster, MD; Jean-Benoît Martinot, MD; Pieter Goeminne, MD, PhD; Hong Nguyen, MD; Eef Vanderhelst, MD, PhD; Charles Pilette, MD, PhD; Ann-Catherine Soenen, MD; Nikolaas De Maeyer, MD; Aurelie Derweduwen, MD; Bernard Bouckaert, MD; Patrick Alexander, MD; Emmanuelle Papleux, MD; Rob Schildermans, MD.

Contributors Writing-original draft: IG. Writing-review and editing: PV, WJ and RV.

Funding The authors have not declared a specific grant for this research from any funding agency in the public, commercial or not-for-profit sectors.

Competing interests IG has nothing to disclose. WJ reports grants from Research Fund Flanders (FWO), grants and personal fees from Astra Zeneca, grants and personal fees from Chiesi, and is cofounder of ArtiQ, outside the submitted work. PV has nothing to disclose. RV reports grants from Research Foundation Flanders, outside the submitted work. There was no specific funding for this manuscript. The manuscript, the abstract or the figures have never been published or presented.

Patient consent for publication Not required. 
Provenance and peer review Not commissioned; externally peer reviewed.

Data availability statement Data sharing not applicable as no datasets generated and/or analysed for this study.

Supplemental material This content has been supplied by the author(s). It has not been vetted by BMJ Publishing Group Limited (BMJ) and may not have been peer-reviewed. Any opinions or recommendations discussed are solely those of the author(s) and are not endorsed by BMJ. BMJ disclaims all liability and responsibility arising from any reliance placed on the content. Where the content includes any translated material, BMJ does not warrant the accuracy and reliability of the translations (including but not limited to local regulations, clinical guidelines, terminology, drug names and drug dosages), and is not responsible for any error and/or omissions arising from translation and adaptation or otherwise.

Open access This is an open access article distributed in accordance with the Creative Commons Attribution Non Commercial (CC BY-NC 4.0) license, which permits others to distribute, remix, adapt, build upon this work non-commercially, and license their derivative works on different terms, provided the original work is properly cited, appropriate credit is given, any changes made indicated, and the use is non-commercial. See: http://creativecommons.org/licenses/by-nc/4.0/.

ORCID iD

Iwein Gyselinck http://orcid.org/0000-0002-4068-7228

\section{REFERENCES}

1 WHO. Coronavirus disease 2019 (COVID-19) situation report-107. 2020. Available: https://www.who.int/emergencies/diseases/novelcoronavirus-2019/situation-reports

2 Zhou F, Yu T, Du R, et al. Clinical course and risk factors for mortality of adult inpatients with COVID-19 in Wuhan, China: a retrospective cohort study. Lancet 2020;395:1054-62.

3 Liu Y, Yan L-M, Wan L, et al. Viral dynamics in mild and severe cases of COVID-19. Lancet Infect Dis 2020;20:656-7.

4 Guan W, Ni Z, Hu Y. Clinical characteristics of coronavirus disease 2019 in China. N Engl J Med 2020:1-13.

5 Nitulescu GM, Paunescu H, Moschos SA, et al. Comprehensive analysis of drugs to treat SARS-CoV-2 infection: mechanistic insights into current COVID-19 therapies (review). Int $\mathrm{J} \mathrm{Mol} \mathrm{Med}$ 2020;46:467-88.

6 Horby P, Lim W, et al. Dexamethasone in hospitalized patients with Covid-19 - preliminary report. N Engl J Med 2020.

7 Stebbing J, Phelan A, Griffin I, et al. COVID-19: combining antiviral and anti-inflammatory treatments. Lancet Infect Dis 2020;20:400-2.

8 Tang N, Bai H, Chen X, et al. Anticoagulant treatment is associated with decreased mortality in severe coronavirus disease 2019 patients with coagulopathy. J Thromb Haemost 2020;18:1094-9.

9 Zarogoulidis P, Papanas N, Kioumis I, et al. Macrolides: from in vitro anti-inflammatory and immunomodulatory properties to clinical practice in respiratory diseases. Eur $\mathrm{J}$ Clin Pharmacol 2012;68:479-503.

10 Ishaqui AA, Khan AH, Sulaiman SAS, et al. Assessment of efficacy of Oseltamivir-Azithromycin combination therapy in prevention of Influenza-A (H1N1)pdm09 infection complications and rapidity of symptoms relief. Expert Rev Respir Med 2020;14:533-41.

$11 \mathrm{Min} \mathrm{J}-\mathrm{Y}$, Jang YJ. Macrolide therapy in respiratory viral infections. Mediators Inflamm 2012;2012:1-9.

12 Walkey AJ, Wiener RS. Macrolide antibiotics and survival in patients with acute lung injury. Chest 2012;141:1153-9.

13 Guo Y-R, Cao Q-D, Hong Z-S, et al. The origin, transmission and clinical therapies on coronavirus disease 2019 (COVID-19) outbreak - an update on the status. Mil Med Res 2020;7:1-10.

14 Mason RJ. Early view pathogenesis of COVID-19 from a cell biologic perspective. Eur res 2020.

15 Hoffmann M, Kleine-Weber H, Schroeder S, et al. SARS-CoV-2 cell entry depends on ACE2 and TMPRSS2 and is blocked by a clinically proven protease inhibitor. Cell 2020;181:271-80.

16 Huang $C$, Wang Y, Li X, et al. Clinical features of patients infected with 2019 novel coronavirus in Wuhan, China. Lancet 2020;395:497-506.

17 Lee Y-L, Liao C-H, Liu P-Y, et al. Dynamics of anti-SARS-Cov-2 $\operatorname{lgM}$ and IgG antibodies among COVID-19 patients. $J$ Infect 2020;81:e55-8.

18 Chen G, Wu D, Guo W, et al. Clinical and immunological features of severe and moderate coronavirus disease 2019. J Clin Invest 2020;130:2620-9.

19 Rouse BT, Sehrawat S. Immunity and immunopathology to viruses: what decides the outcome? Nat Rev Immunol 2010;10:514-26.
20 Blanco-Melo D, Nilsson-Payant BE, Liu W-C, et al. Imbalanced host response to SARS-CoV-2 drives development of COVID-19. Cell 2020;181:1036-45.

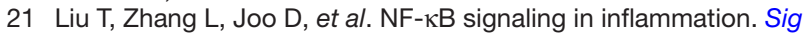
Transduct Target Ther 2017;2.

22 Zhao Y, Qin L, Zhang P, et al. Longitudinal COVID-19 profiling associates IL-1ra and IL-10 with disease severity and RANTES with mild disease. JCl Insight 2020;5. doi:10.1172/jci.insight.139834. [Epub ahead of print: 09 Jul 2020].

23 Qin C, Zhou L, Hu Z, et al. Dysregulation of immune response in patients with coronavirus 2019 (COVID-19) in Wuhan, China. Clin Infect Dis 2020;71:762-8.

24 Yap JKY, Moriyama M, Iwasaki A. Inflammasomes and pyroptosis as therapeutic targets for COVID-19. J Immunol 2020;205:307-312.

25 Wang J, Jiang M, Chen X, et al. Cytokine storm and leukocyte changes in mild versus severe SARS-CoV-2 infection: review of 3939 COVID-19 patients in China and emerging pathogenesis and therapy concepts. J Leukoc Biol 2020;108:17-41.

26 Diao B, Wang C, Tan Y, et al. Reduction and functional exhaustion of T cells in patients with coronavirus disease 2019 (COVID-19). Front Immunol 2020;11:827 https://www.frontiersin.org/article/

27 Feng Z, Diao B. The novel severe acute respiratory syndrome coronavirus 2 (SARS-CoV-2) directly Decimates human spleens and lymph nodes. medRxiv 2020.

28 Wang F, Nie J, Wang H, et al. Characteristics of peripheral lymphocyte subset alteration in COVID-19 pneumonia. $J$ Infect Dis 2020;221:1762-9.

29 Michaud V, Deodhar M, Arwood M, et al. Ace2 as a therapeutic target for COVID-19; its role in infectious processes and regulation by modulators of the RaaS system. J Clin Med 2020;9:2096-26.

30 Ackermann M, Verleden SE, Kuehnel M. Pulmonary vascular Endothelialitis, thrombosis, and angiogenesis in Covid-19. N Engl J Med.

31 Lechowicz K, Drożdżal S, Machaj F, et al. COVID-19: the potential treatment of pulmonary fibrosis associated with SARS-CoV-2 infection. J Clin Med 2020;9:1917.

$32 \mathrm{Xu}$ J, Xu X, Jiang L, et al. SARS-CoV-2 induces transcriptional signatures in human lung epithelial cells that promote lung fibrosis. Respir Res 2020;21:1-12.

33 Rubinstein E. Comparative safety of the different macrolides. Int $\mathrm{J}$ Antimicrob Agents 2001;18 Suppl 1:71-6.

34 Zimmermann P, Ziesenitz VC, Curtis N, et al. The immunomodulatory effects of macrolides-A systematic review of the underlying mechanisms. Front Immunol 2018;9:302.

35 Di Paolo A, Barbara C, Chella A, et al. Pharmacokinetics of azithromycin in lung tissue, bronchial washing, and plasma in patients given multiple oral doses of 500 and $1000 \mathrm{Mg}$ daily. Pharmacol Res 2002;46:545-50.

36 Wildfeuer A, Laufen H, Zimmermann T. Uptake of azithromycin by various cells and its intracellular activity under in vivo conditions. Antimicrob Agents Chemother 1996;40:75-9.

37 Jaruratanasirikul S, Hortiwakul R, Tantisarasart T, et al. Distribution of azithromycin into brain tissue, cerebrospinal fluid, and aqueous humor of the eye. Antimicrob Agents Chemother 1996;40:825-6.

38 Bridwell R, Long B, Gottlieb M. Neurologic complications of COVID-19. Am J Emerg Med 2020;38:1549.e3-1549.e7.

39 Ellul MA, Benjamin L, Singh B, et al. Neurological associations of COVID-19. Lancet Neurol 2020;19:767-83.

$40 \mathrm{Wu}$ J, Tang Y. Revisiting the immune balance theory: a neurological insight into the epidemic of COVID-19 and its alike. Front Neurol 2020;11:1230.

41 Damle B, Vourvahis M, Wang E, et al. Clinical pharmacology perspectives on the antiviral activity of azithromycin and use in COVID-19. Clin Pharmacol Ther 2020;108:201-11.

42 Kawamura K, Ichikado K, Takaki M, et al. Adjunctive therapy with azithromycin for moderate and severe acute respiratory distress syndrome: a retrospective, propensity score-matching analysis of prospectively collected data at a single center. Int $J$ Antimicrob Agents 2018;51:918-24.

43 Gielen V, Johnston SL, Edwards MR. Azithromycin induces anti-viral responses in bronchial epithelial cells. Eur Respir $J$ 2010;36:646-54

44 Zeng S, Meng X, Huang Q, et al. Spiramycin and azithromycin, safe for administration to children, exert antiviral activity against enterovirus A71 in vitro and in vivo. Int J Antimicrob Agents 2019;53:362-9.

45 Sandeep S, McGregor K. Energetics Based Modeling of Hydroxychloroquine and Azithromycin Binding to the SARS-CoV-2 Spike (S)Protein - ACE2 Complex. ChemRxiv 2020.

46 Fantini J, Chahinian H, Yahi N. Synergistic antiviral effect of hydroxychloroquine and azithromycin in combination against 
SARS-CoV-2: what molecular dynamics studies of virus-host interactions reveal. Int J Antimicrob Agents 2020;56:106020.

47 Nouwen LV, Everts B. Pathogens mentoring macrophages and dendritic cells: manipulation of mTOR and cellular metabolism to promote immune escape. Cells 2020;9:161-23.

48 Kindrachuk J, Ork B, Hart BJ, et al. Antiviral potential of ERK/ MAPK and PI3K/Akt/mTOR signaling modulation for middle East respiratory syndrome coronavirus infection as identified by temporal kinome analysis. Antimicrob Agents Chemother 2015;59:1088-99.

49 Ratzinger F, Haslacher H, Poeppl W, et al. Azithromycin suppresses CD4(+) T-cell activation by direct modulation of mTOR activity. Sci Rep 2014;4:7438.

50 Li C, Zu S, Deng Y-Q, et al. Azithromycin protects against Zika virus infection by upregulating virus-induced type I and III interferon responses. Antimicrob Agents Chemother 2019;63:1-14.

51 Porter JD, Watson J, Roberts LR, et al. Identification of novel macrolides with antibacterial, anti-inflammatory and type I and III IFN-augmenting activity in airway epithelium. J Antimicrob Chemother 2016;71:2767-81.

52 Slater M, Torr E, Harrison T, et al. The differential effects of azithromycin on the airway epithelium in vitro and in vivo. Physiol Rep 2016;4:e12960-15.

53 Takahashi E, Indalao IL, Sawabuchi T, et al. Clarithromycin suppresses induction of monocyte chemoattractant protein-1 and matrix metalloproteinase- 9 and improves pathological changes in the lungs and heart of mice infected with influenza A virus. Comp Immunol Microbiol Infect Dis 2018;56:6-13.

54 Stellari FF, Sala A, Donofrio G, et al. Azithromycin inhibits nuclear factor- $\kappa$ B activation during lung inflammation: an in vivo imaging study. Pharmacol Res Perspect 2014;2:1-12.

55 Haydar D, Cory TJ, Birket SE, et al. Azithromycin polarizes macrophages to an M2 phenotype via inhibition of the STAT1 and NF-кB signaling pathways. J Immunol 2019;203:1021-30.

56 Fernandez AD, Elmore MK, Metzger DW. Azithromycin modulates murine immune responses to pneumococcal conjugate vaccine and inhibits nasal clearance of bacteria. J Infect Dis 2004;190. doi:10.1086/425038. [Epub ahead of print: 13 Oct 2004].

57 Nguyen AA, Habiballah SB, Platt CD, et al. Immunoglobulins in the treatment of COVID-19 infection: proceed with caution! Clin Immunol 2020;216:108459.

58 Parnham MJ, Haber VE, Giamarellos-Bourboulis EJ, et al. Azithromycin: mechanisms of action and their relevance for clinical applications. Pharmacol Ther 2014;143:225-45.

59 Zuo Y, Yalavarthi S, Shi H, et al. Neutrophil extracellular traps in COVID-19. JCI Insight 2020;5:1-11 https://doi.org/

60 Cory TJ, Birket SE, Murphy BS, et al. Azithromycin increases in vitro fibronectin production through interactions between macrophages and fibroblasts stimulated with Pseudomonas aeruginosa. J Antimicrob Chemother 2013;68:840-51.

61 Willems-Widyastuti A, Vanaudenaerde BM, Vos R, et al. Azithromycin attenuates fibroblast growth factors induced vascular endothelial growth factor via p38(MAPK) signaling in human airway smooth muscle cells. Cell Biochem Biophys 2013;67:331-9.

62 Beović B, Doušak M, Ferreira-Coimbra J, et al. Antibiotic use in patients with COVID-19: a 'snapshot' Infectious Diseases International Research Initiative (ID-IRI) survey. J Antimicrob Chemother 2020;75:3386-90.

63 Chertow DS, Memoli MJ. Bacterial coinfection in influenza: a grand rounds review. JAMA 2013;309:275-82.

64 Lansbury L, Lim B, Baskaran V, et al. Co-Infections in people with COVID-19: a systematic review and meta-analysis. J Infect 2020;81:266-75.

65 Kawamura K, Ichikado K, Takaki M, et al. Efficacy of azithromycin in sepsis-associated acute respiratory distress syndrome: a retrospective study and propensity score analysis. Springerplus 2016;5:1-7.

66 Lee N, Wong C-K, Chan MCW, et al. Anti-Inflammatory effects of adjunctive macrolide treatment in adults hospitalized with influenza: a randomized controlled trial. Antiviral Res 2017;144:48-56.

67 Arabi YM, Deeb AM, Al-Hameed F, et al. Macrolides in critically ill patients with middle East respiratory syndrome. Int $\mathrm{J}$ Infect Dis 2019;81:184-90.

68 Gautret P, Lagier J-C, Parola P, et al. Hydroxychloroquine and azithromycin as a treatment of COVID-19: results of an openlabel non-randomized clinical trial. Int $J$ Antimicrob Agents 2020;56:105949.

69 Gautret P, Lagier J-C, Parola P, et al. Clinical and microbiological effect of a combination of hydroxychloroquine and azithromycin in 80 COVID-19 patients with at least a six-day follow up: a pilot observational study. Travel Med Infect Dis 2020;34:101663.
70 Albani F, Fusina F, Giovannini A, et al. Impact of azithromycin and or hydroxychloroquine on hospital mortality in COVID-19. J Clin Med 2020;9:2800.

71 Kuderer NM, Choueiri TK, Shah DP, et al. Clinical impact of COVID-19 on patients with cancer (CCC19): a cohort study. Lancet 2020;395:1907-18.

72 Arshad S, Kilgore P, Chaudhry ZS, et al. Treatment with hydroxychloroquine, azithromycin, and combination in patients hospitalized with COVID-19. Int J Infect Dis 2020;97:396-403.

73 Guérin V, Lévy P, Thomas J-L, et al. Azithromycin and hydroxychloroquine accelerate recovery of outpatients with Mild/ Moderate COVID-19. AJMAH 2020:45-55.

74 Szente Fonseca SN, de Queiroz Sousa A, Wolkoff AG, et al. Risk of hospitalization for Covid-19 outpatients treated with various drug regimens in Brazil: comparative analysis. Travel Med Infect Dis 2020;38:38.

75 Rosenberg ES, Dufort EM, Udo T, et al. Association of treatment with hydroxychloroquine or azithromycin with in-hospital mortality in patients with COVID-19 in New York state. JAMA 2020;323:2493-502.

76 Cavalcanti AB, Zampieri FG, Rosa RG. Hydroxychloroquine with or without azithromycin in mild-to-moderate Covid-19. N Engl J Med.

77 Das RR, Jaiswal N, Dev N, et al. Efficacy and safety of anti-malarial drugs (chloroquine and Hydroxy-Chloroquine) in treatment of COVID-19 infection: a systematic review and meta-analysis. Front Med 2020;7:482.

78 Mercuro NJ, Yen CF, Shim DJ, et al. Risk of QT interval prolongation associated with use of hydroxychloroquine with or without concomitant azithromycin among hospitalized patients testing positive for coronavirus disease 2019 (COVID-19). JAMA Cardiol 2020;5:e201834:1036.

79 Saleh M, Gabriels J, Chang D, et al. Effect of chloroquine, hydroxychloroquine, and azithromycin on the corrected QT interval in patients with SARS-CoV-2 infection. Circ Arrhythm Electrophysiol 2020;13:e008662.

80 Pothen L, Yildiz H, De Greef J, et al. Safe use of hydroxychloroquine and its combination with azithromycin in the context of Sars-CoV-2 outbreak: clinical experience in a Belgian tertiary center. Travel Med Infect Dis 2020;36:101788.

81 ClinicalTrials.gov [Internet]. Oxford: University of Oxford (United Kingdom). 2000 Feb 29-. identifier NCT04381936. randomised evaluation of COVID-19 therapy (recovery), 2020. Available: https:// clinicaltrials.gov/ct2/s [Accessed 3 Sep 2020].

82 Esper RB, da Silva RS, Costa Oikawa FT. Empirical treatment with hydroxychloroquine and azithromycin for suspected cases of COVID-19 followed-up by telemedicine 2020:1-25.

83 ClinicalTrials.gov [Internet]. Oxford: University of Oxford (United Kingdom). 2000 Feb 29-. identifier NCT04381962. A multicentre open-label Two-arm randomised superiority clinical trial of azithromycin versus usual care in ambulatory COVID19 (ATOMIC2); 2.

84 ClinicalTrials.gov [Internet]. San Fransisco: University of California (US). 2000 Feb 29-. identifier NCT04332107. azithromycin for COVID-19 treatment in outpatients nationwide (action), 2020. Available: https://clinica. 2020;:2020 [Accessed 3 Sep 2020].

85 Muthuri SG, Venkatesan S, Myles PR. Impact of neuraminidase inhibitors on influenza A (H1N1) pdm09-related pneumonia : an individual participant data meta-analysis. Influenza Other Respi Viruses 2015:192-204.

86 Zhang W, Zhao Y, Zhang F, et al. The use of anti-inflammatory drugs in the treatment of people with severe coronavirus disease 2019 (COVID-19): the perspectives of clinical immunologists from China. Clin Immunol 2020;214:108393-5.

87 Mathioudakis AG, Fally M, Hashad R, et al. COVID-19 clinical trials: unraveling a methodological Gordian knot. Am J Respir Crit Care Med 2020;202:635-7.

88 Tanriverdİ E, ÇÖrtÜk M, Yildirim Bİnnaz Zeynep, et al. The use of hydroxychloroquine plus azithromycin and early hospital admission are beneficial in Covid-19 patients: turkey experience with real-life data. Turk J Med Sci 2020. doi:10.3906/sag-2005-82. [Epub ahead of print: 19 Jul 2020].

89 d'Arminio MA, Tavelli A, Bai F. Since January 2020 Elsevier has created a COVID-19 resource centre with free information in English and mandarin on the novel coronavirus COVID- 19. The COVID-19 resource centre is hosted on Elsevier connect, the company ' S public news and information. Int J Infect Dis 2020;99:75-6.

90 Sekhavati E, Jafari F, SeyedAlinaghi S, et al. Safety and effectiveness of azithromycin in patients with COVID-19: an openlabel randomised trial. Int J Antimicrob Agents 2020;56:106143. 
91 Lauriola M, Pani A, Ippoliti G, et al. Effect of combination therapy of hydroxychloroquine and azithromycin on mortality in patients with COVID-19. Clin Trans/ Sci 2020;13:1071-6.

92 Geleris J, Sun Y, Platt J. Observational study of hydroxychloroquine in hospitalized patients with Covid-19. N Engl J Med 2020:1-8.

93 Ip A, Berry DA, Hansen E, et al. Hydroxychloroquine and tocilizumab therapy in COVID-19 patients-An observational study. PLoS One 2020;15:e0237693.

94 Rodríguez-Molinero A, Pérez-López C, Gálvez-Barrón C, et al. Observational study of azithromycin in hospitalized patients with COVID-19. PLoS One 2020;15:e0238681-13.

95 Lammers AJJ, Brohet RM, Theunissen REP, et al. Early hydroxychloroquine but not chloroquine use reduces ICU admission in COVID-19 patients. Int $J$ Infect Dis 2020;101:283-9.

96 Satlin MJ, Goyal P, Magleby R, et al. Safety, tolerability, and clinical outcomes of hydroxychloroquine for hospitalized patients with coronavirus 2019 disease. PLoS One 2020;15:e0236778.
97 Magagnoli J, Narendran S, Pereira F, et al. Outcomes of hydroxychloroquine usage in United States veterans hospitalized with COVID-19. Med 2020;1:114-27.

98 Ayerbe L, Risco-Risco C, Ayis S. The association of treatment with hydroxychloroquine and hospital mortality in COVID-19 patients. Intern Emerg Med 2020;15:1501-6.

99 Young AM, Marshall A, Thirlwall J, et al. Comparison of an oral factor Xa inhibitor with low molecular weight heparin in patients with cancer with venous thromboembolism: results of a randomized trial (SELECT-D). J Clin Oncol 2018;36:2017-23.

100 Furtado RHM, Berwanger O, Fonseca HA. Azithromycin in addition to standard of care versus standard of care alone in the treatment of patients admitted to the hospital with severe COVID-19 in Brazil (coalition II): a randomised clinical trial. Lancet. 